\title{
Carcinoma Adenoescamoso do Reto: Relato de Caso
}

\author{
Adenosquamous Rectal Carcinoma: A Case Report \\ ANDRÉ LUIGI PINCINATO ${ }^{1}$; FLÁVIABALSAMO $^{2}$; JULIANAMAGALHÃES LOPES ${ }^{1}$; RODRIGO BRITTO DE \\ CARVALHO $^{1}$; ALLINE MACIEL PINHEIRO BORGES ${ }^{1}$; GALDINO JOSÉ SITONIO FORMIGA ${ }^{3}$
${ }^{1}$ Residentes do Serviço de Coloproctologia do Hospital Heliópolis - São Paulo, SP; ${ }^{2}$ Assistente do Serviço de Coloproctologia do Hospital Heliópolis - São Paulo, SP, ${ }^{3}$ Chefe do Serviço de Coloproctologia do Hospital Heliópolis - São Paulo, SP.

PINCINATO AL; BALSAMO F; LOPES JM; CARVALHO RB; BORGES AMP; FORMIGA GJS. Carcinoma adenoescamoso do reto: relato de caso. Rev bras Coloproct, 2008;28(1): 095-098.

RESUMO: Os carcinomas adenoescamosos são neoplasias bastante raras que ocorrem mais freqüentemente no reto e porções distais do cólon. A apresentação clínica e macroscópica destas lesões não difere do adenocarcinoma. Relata-se um caso de tumor adenoescamoso do reto, cuja confirmação diagnóstica somente foi realizada após a cirurgia de ressecção tumoral e estudo imunohistoquímico.

Descritores: Carcinoma adenoescamoso, neoplasia, reto, cólon, carcinogênese.

\section{INTRODUÇÃO}

Os carcinomas adenoescamosos de cólon e reto são definidos como tumores cujos componentes escamosos e glandulares coexistem, e ambos têm potencial de originar metástases. ${ }^{1-3}$ É uma entidade extremamente rara, com incidência de 0,025 a $0,2 \%$ de todos os tumores malignos do intestino grosso. ${ }^{1,2,4}$

O primeiro caso descrito foi por Herxheimer, em 1907, um carcinoma adenoescamoso de ceco. Em 1909, Probst relata um caso acometendo sigmóide. ${ }^{5}$

A patogênese não é bem definida e existem diversas teorias para explicar a existência das duas linhagens celulares concomitantes. . $^{2,3,6}$

A localização dos tumores é principalmente em reto e porções distais do cólon, com apresentação clínica e macroscópica semelhante ao adenocarcinoma, porém com menor sobrevida. ${ }^{1,4}$

O objetivo deste estudo é relatar um caso de tumor adenoescamoso do reto e apresentar revisão da literatura.

\section{RELATO DO CASO}

J.L.F, 56 anos, masculino, branco, natural e procedente de São Paulo, S.P. Há oito meses com puxo, tenesmo, mucorréia, hematoquezia e alteração do hábito intestinal de uma para três vezes por dia. Não apresentava emagrecimento ou qualquer antecedente patológico prévio. Submetido a exame físico geral e proctológico que evidenciou lesão úlcero-vegetante de 10 a $13 \mathrm{~cm}$ da margem anal, em parede anterior, não transponível ao aparelho rígido, cujo anátomo-patológico resultou em adenocarcinoma túbulo-viloso. Realizou colonoscopia que também demonstrou imperviedade da lesão. O CEA pré-operatório foi 333,5 ng/dl. TC de abdome e pelve: sem metástases hepáticas (Figura1), com espessamento da parede retal e borramento da gordura peri-retal (Figura 2). Raio-x de tórax: sem alterações.

Foi submetido à retossigmoidectomia anterior com anastomose término-terminal e transversostomia derivativa. Visualizada no intra-operatório lesão nodular

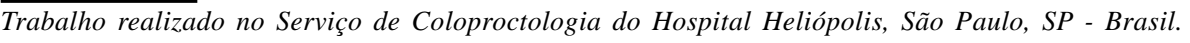

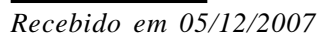

Aceito para publicação em 26/02/2008 
de $2 \mathrm{~cm}$ de diâmetro em segmento VIII hepático, sugestiva de implantação secundária. $\mathrm{O}$ anátomo-patológico da peça cirúrgica diagnosticou carcinoma adenoescamoso de retossigmóide confirmando o componente escamoso pela imuno-histoquímica (anticorpo 34âH12 positivo - citoqueratina de alto peso molecular) (Figuras 3 e 4).

Realizou tratamento quimioterápico adjuvante com 5-fluorouracil e leucovorin. Após novo estadiamento, foi submetido à laparotomia exploradora com intuito de ressecção da metástase hepática com achado de múltiplas pequenas metástases hepáticas em ambos os lobos, além da lesão previamente conhecida, optando-se apenas pela realização de biópsias. A microscopia revelou infiltração de adenocarcinoma tubular no fígado (Figura 5).

O paciente foi encaminhado posteriormente à quimioterapia paliativa, não realizada devido à insu-

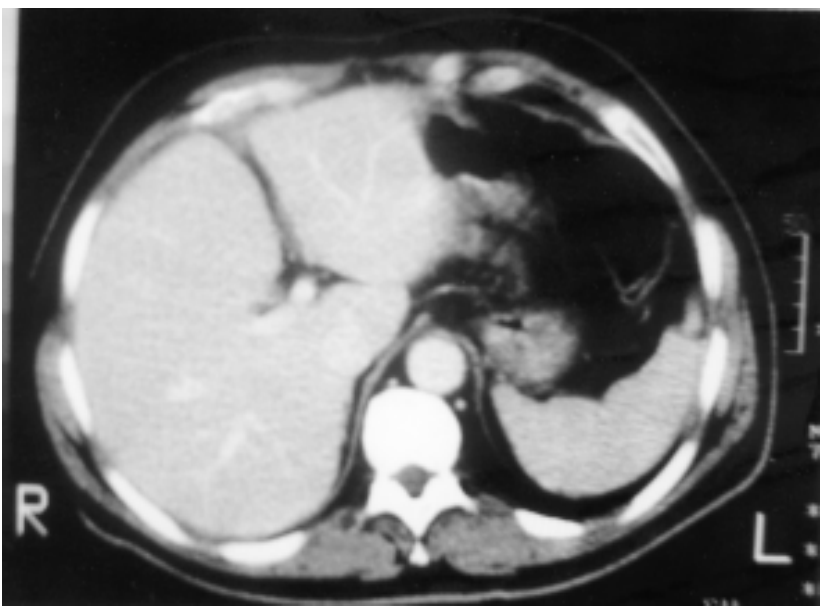

Figura 1 - TC de abdome - ausência de metástases hepáticas.

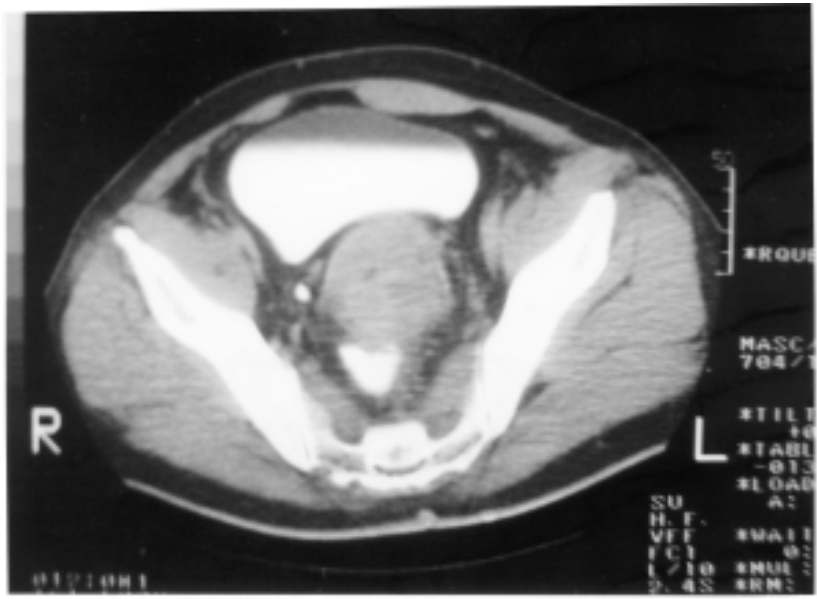

Figura 2 - TC de pelve - espessamento da parede do reto. ficiência hepática, evoluindo para óbito 11 meses após o diagnóstico.

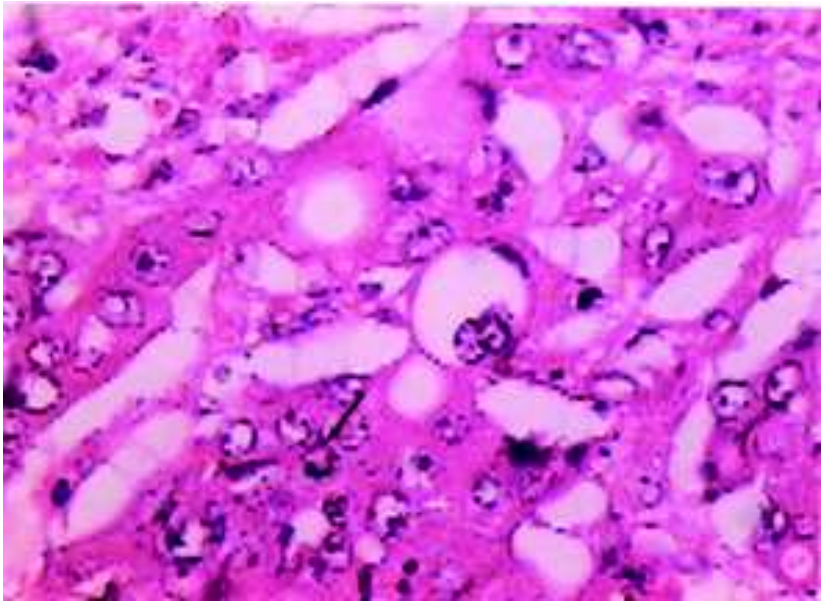

Figura 3-Células com padrão tubular e área com células epiteliais sem diferenciação glandular (seta), HE, 100x.

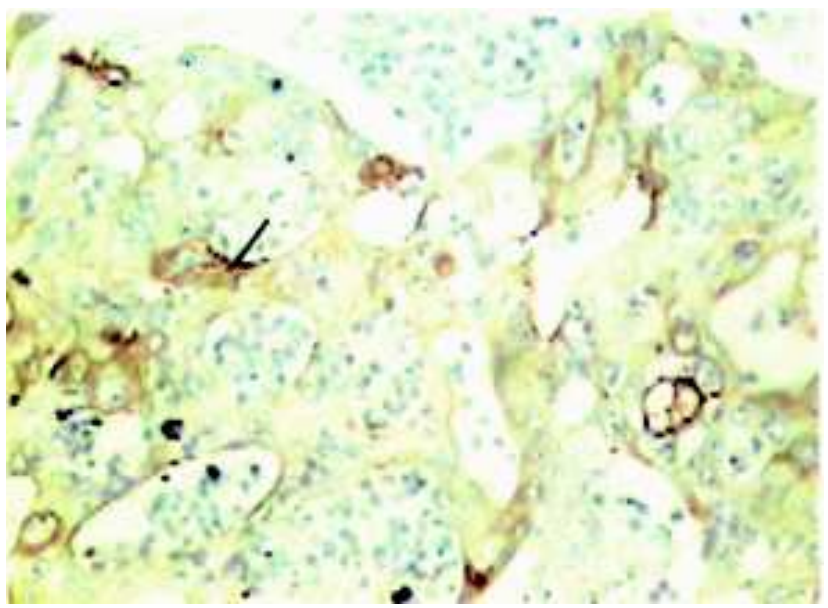

Figura 4-Imuno-histoquímica com células coradas com anticorpo $34 \beta H 12$ (seta), $20 x$.

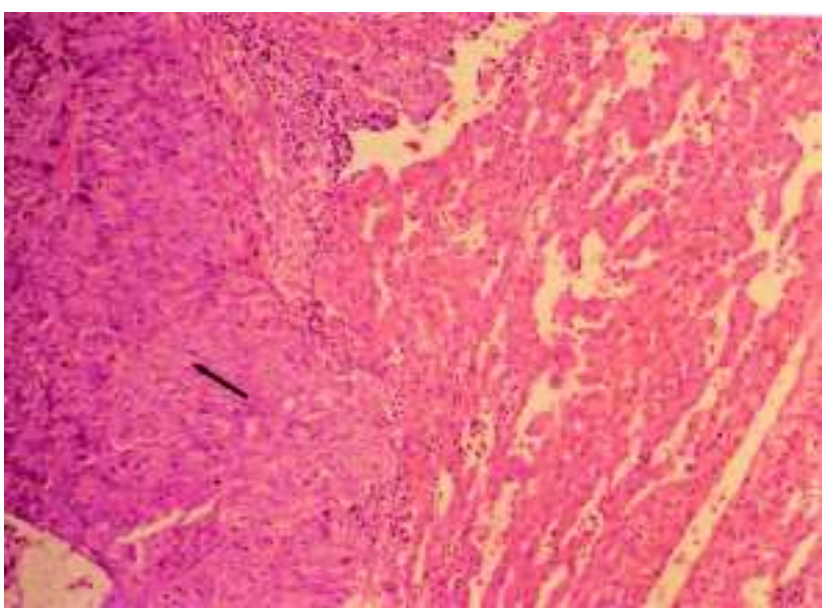

Figura 5 - Infiltração de adenocarcinoma (seta) no fígado, aumento de $100 x$. 


\section{DISCUSSÃO}

O carcinoma adenoescamoso é uma entidade extremamente rara, conseqüentemente, a literatura a respeito deste tumor é limitada. ${ }^{2}$ A frequiência é maior entre caucasianos $(84 \%)$ do que entre afro-americanos $(15 \%)$ e outras raças $(1 \%){ }^{4}$

Como no adenocarcinoma, o reto e as porções distais do cólon são os locais mais freqüentemente afetados. ${ }^{1,2,4,7}$

Diversas teorias foram propostas para explicar a origem do carcinoma adenoescamoso de cólon. A presença de restos embrionários heterotópicos do epitélio escamoso na mucosa colônica não é sustentada, assim como, a transformação de células glandulares em escamosas. ${ }^{8}$

Um estímulo anormal da mucosa pode resultar em diferenciação aberrante como na colite ulcerativa, esquistossomose, radiação, e infecção pelo papiloma vírus humano. ${ }^{2,5,7}$ A metaplasia escamosa pode ocorrer em até $1 \%$ dos adenomas colônicos, e poderia ser uma causa para este tumor. ${ }^{7}$

Outra possível origem é ser de uma célula pluripotencial (steam cell), com capacidade de diferenciação multidirecional. Esta teoria é corroborada por estudos de microscopia eletrônica, onde a ultraestrutura das células sugere que a diferenciação glandular e escamosa, origina-se de uma única célula progenitora. ${ }^{8}$

A apresentação clínica é similar a do adenocarcinoma incluindo sangramento retal, tenesmo, dor, mudança do hábito intestinal e perda de peso, ${ }^{3,7}$ como evidenciado no relato do caso, com a duração dos sintomas muito variável, desde semanas a vários meses. ${ }^{7}$ A associação com colite ulcerativa, hipercalcemia, polipose múltipla, câncer ginecológico e esquistossomose é relatada. ${ }^{9}$

Lesões sincrônicas e metacrônicas com adenocarcinoma também são citadas, sugerindo que esses tumores podem não se apresentar como neoplasias solitárias, e merecem um seguimento apropriado. $^{2,5}$

Metástases ocorrem para linfonodos, fígado, peritônio, pulmão e ossos, ${ }^{5}$ sendo que os componentes escamoso, e glandular ou ambos podem metastatizar. Existe uma certa tendência de aumento do componente escamoso nas metástases. ${ }^{6}$ Em nosso caso, as metástases foram decorrentes da disseminação de adenocarcinoma para o fígado.

A investigação pré-operatória é similar ao adenocarcinoma, e a biópsia, seja incisional ou excisional, é a única forma de distingüí-lo. ${ }^{1,7}$ A suspeita deve surgir em adenocarcinoma com áreas de tumor muito pouco diferenciado devendo ser pesquisados com imunoperoxidase e/ou microscopia eletrônica para identificação do componente escamoso. ${ }^{6}$

O prognóstico de tumores estádio I e II com linfonodo negativo (Dukes A e B) é semelhante ao adenocarcinoma. Porém, na doença nodal, o prognóstico é pior. ${ }^{2,5}$ A maioria dos pacientes é diagnosticada em fases avançadas da doença, e a sobrevida após o diagnóstico é de aproximadamente nove meses. ${ }^{1}$

No caso descrito, o paciente apresentava metástases hepáticas no momento do diagnóstico, e a sobrevida foi de 11 meses, corroborando os dados da literatura.

A cirurgia é o tratamento de escolha, e segue os mesmos princípios do adenocarcinoma. ${ }^{4}$ A terapia adjuvante tem sido usada como tratamento do carcinoma adenoescamoso, mas o benefício é desconhecido pela raridade da lesão. Os agentes adjuvantes quimioterápicos mais comumente usados são: 5fluorouracil, semustine, carmustine e methotrexate para estádios C. ${ }^{2}$ Há relatos de bons resultados com esquema Nigro com 5-fluorouracil e mitomicina e radioterapia de 4500 cGy para lesões anorretais. ${ }^{4,7}$

Apesar da terapia adjuvante não ter beneficio comprovado, seu uso é teoricamente benéfico.

\footnotetext{
ABSTRACT: The adenosquamous carcinomas are rare and occur in the lower part of the colon and rectum. Their symptomatology and macroscopy do not differ from adenocarcinoma lesions. We report an adenosquamous rectal tumor which diagnosis was confirmed only after tumor resection and immunocytochemical study.
}

Key words: Adenosquamous carcinoma, neoplasm, rectum, colon, carcinogenesis. 


\section{REFERÊNCIAS}

1. Schlegel R D, Dehni N, Cravino AT, et al. Primary adenosquamous carcinoma of the rectum. Report of 4 cases and review of the literature. Colorectal Dis. 2001; 3(3): 201-3.

2. Petrelli N J, Valle A A, Weber T K, et al. Adenosquamous carcinoma of colon and rectum. Dis Colon Rectum 1996; 39: 1265-8.

3. Rubio C A, Collins V P, Berg C. Mixed adenosquamous carcinoma of the cecum: report of a case and review of the literature. Dis Colon Rectum 1981; 24: 301-4.

4. Cagir B, Nagy M W, Topham A, et al. Adenosquamous carcinoma of the colon, rectum and anus: epidemiology, distribution and survival characteristics. Dis Colon Rectum 1999; 42: 25863.

5. Frizelle FA, Hobday KS, Batts KP, et al. Adenosquamous and squamous carcinoma of the colon and upper rectum: a clinical and fistopathologic study. Dis Colon Rectum 2001; 44: 341346.

6. Cerezo L, Alvarez M, Edwards O, Price G-Adenosquamous carcinoma of the colon. Dis Colon Rectum 1985; 28: 597-603.
7. Schneider TA II, Birkett D H, Vernava AM III - Primary adenosquamous and squamous cell carcinoma of the colon and rectum. Int J Cotorectal Dis 1992; 7: 144-7.

8. Kontozoglou T E, Moyana T N - Adenosquamous carcinoma of the colon - an immunocytochemical and ultrastructural study: report of two cases and review of the literature. Dis Colon Rectum 1989; 32: 716-21.

9. Peonim V, Thakemgpol K, Pacharee P, Stitnimankam T Adenosquamous carcinoma and carcinoidal differentiation of the colon. Report of a case. Cancer 1983; 52: 1122-5.

\section{Endereço para correspondência:}

FLÁVIA BALSAMO

Serviço de Coloproctologia do Hospital Heliópolis R. Cônego Xavier, 276- Vila Heliópolis 04231-030- São Paulo, SP

Tel.: 11- 2274-7600 (ramal 244)

Fax: 11-2247-7646

E-mail: flabal@uol.com.br 